\title{
Erratum to: National Adaptation Strategies, what else? Comparing adaptation mainstreaming in German and Dutch water management
}

\author{
Anja Bauer $\cdot$ Reinhard Steurer
}

Published online: 14 February 2015

(c) Springer-Verlag Berlin Heidelberg 2015

\section{Erratum to: Reg Environ Change (2015) 15:341-352 DOI 10.1007/s10113-014-0655-3}

The original version of this article unfortunately contained a mistake in the abstract section. The sixth line of the abstract contains an error. We provide the full abstract with the corrected sentence as follows:

Over the past decade, governments in many countries began to integrate or mainstream climate change adaptation into a range of sectors. Comprehensive multisectoral adaptation strategies have emerged as the preferred approach across Europe. The German Adaptation Strategy is a prominent example for such a comprehensive strategy. It addresses 14 sectors with national key issues and measures, and it provides orientation for other (mainly sub-national) actors. Against this trend, the Netherlands has pursued climate change adaptation mainly through a sectorally focused approach: the Dutch
Delta Programme. Building on existing programmes, it facilitates analysis and strategy development for longterm water management at a national scale with a strong regional focus. The present paper compares the two dissimilar governance approaches mainly with regard to how and to what degree they mainstream adaptation into water and coastal zone management in selected regions. After discussing strengths and weaknesses of the two approaches, we conclude that the more common multisectoral approach applied in Germany and most other OECD countries is not necessarily superior to sectorally focused approaches. Although the Dutch and the German cases appear to resemble alternatives, we highlight that their combination holds the promise to compensate for each other's weaknesses. Overall, we argue that diversity in the governance of climate change adaptation is desirable because it can help to prevent that several countries fail in similar ways.

The online version of the original article can be found under doi:10.1007/s10113-014-0655-3.

\footnotetext{
A. Bauer $\cdot$ R. Steurer $(\square)$

University of Natural Resources and Life Sciences,

Vienna, Austria

e-mail: reinhard.steurer@boku.ac.at
} 